\title{
STRATEGIES TO MODULATE THE INTERACTION OF NB WITH MICROSTRUCTURE DURING HOT ROLLING OF FLAT PRODUCTS
}

\author{
Beatriz Pereda ' \\ Beatriz Lopez' \\ Jose Maria Rodriguez-lbabe '
}

\begin{abstract}
$\mathrm{Nb}$ microalloying in thermomechanical processes for flat products has been related to its suitability to enhance strain-induced precipitation and obtain a pancaked austenite prior to transformation. As new steel grades or lay-outs are developed, more complex metallurgical conditions need to be evaluated. In this context, $\mathrm{Nb}$ microalloying needs to intervene in a more controlled way in all steps. For instance, the hardenability enhancement related to $\mathrm{Nb}$ to achieve lower temperature transformation products demands an adequate balance of $\mathrm{Nb}$ precipitated during rolling and the one remaining in solid solution. Similar effects are also sought if $\mathrm{Nb}$ is used to increase strength through precipitation hardening. This work evaluates how changes in the rolling strategies affect the interaction between $\mathrm{Nb}(\mathrm{C}, \mathrm{N})$ precipitation and austenite recrystallization during hot rolling. As the interactions are complex, application of microstructural models helps to define the best austenite conditioning and the convenient amount of $\mathrm{Nb}$ in solution as a function of final applications. Several strategies are discussed for both normal and coarse initial austenite grain sizes.
\end{abstract}

Keywords: Nb Microalloying; Thermomechanical Processing; Pancaked Austenite; Intragranular Nucleation.

\section{INTRODUCTION}

Thin slab direct rolling (TSDR) is a technology characterized by a continuous evolution, including both the production of new steel grades and the design of new lay-outs $[1,2]$. In this context, the role of some traditional microalloying elements can spread from their conventional role to new metallurgical applications. For instance, the classical use of $\mathrm{Nb}$ in thermomechanical processes is to promote $\mathrm{Nb}(\mathrm{C}, \mathrm{N})$ strain-induced precipitation during hot rolling to obtain a pancaked austenite prior to transformation. In TSDR, new rolling strategies have been proposed to balance the complex recrystallization-precipitation interactions. For example, some authors have suggested that dynamic recrystallization could be a suitable mechanism to refine the as-cast grains. However, in "typical" TSDR rolling strategies, the activation of dynamic recrystallization in coarse as-cast austenite grains requires the application of high strain levels that may not be easily achieved before $\mathrm{Nb}$ precipitation [3]. Nevertheless, new TSDR lay-outs, in some cases associated with higher or lower initial rolling temperatures than usually applied, open the convenience to reevaluate these aspects. This manuscript analyzes the role of different process parameters that could enhance static or dynamic recrystallization occurrence in $\mathrm{Nb}$ microalloyed grades. The analysis will be performed considering "conventional" initial austenite grain sizes, as those usually present in cold or hot charging, and very coarse austenite grains, as those corresponding to direct charging (as-cast microstructures).

\section{MATERIAL AND METHODS}

Two low carbon Nb microalloyed steels have been selected and their chemistries are summarized in Table I. Laboratory multipass torsion tests were performed following the schedule of Figure I and using the deformation conditions summarized in Table 2. In order to consider different scenarios, the following conditions were evaluated:

- Coarse initial austenite grain size (direct charging simulation), obtained by reheating at $1420^{\circ} \mathrm{C}$;

- Normal initial austenite grain size distribution (reheating at $1250^{\circ} \mathrm{C}$ to put all $\mathrm{Nb}$ into solution);

- Three deformation temperature schedules, summarized in Table 2. In each case, before application of the first deformation pass, a temperature equalizing step was included. Six strain passes were applied, with a total reduction that could correspond to a final sheet thickness of 8-9 mm, considering an initial $60-65 \mathrm{~mm}$ thin slab.

Two tests were performed for each condition. One of the samples was quenched after the deformation sequence to analyze the austenite microstructure, while in the second case, a coiling simulation step was applied at $620^{\circ} \mathrm{C}$ to evaluate the resulting room temperature microstructure. The analysis of $\mathrm{Nb}$ precipitation was done

'Materials and Manufacturing, Ceit and Tecnun, San Sebastian, Guipuzcoa, Spain. E-mail: bpereda@ceit.es 
by TEM in the quenched samples (replica) and in the room temperature microstructures (replica and foils). The study of the softening/hardening mechanisms, affecting austenite evolution during the deformation schedule, was performed with the help of MicroSim ${ }^{\circledR}$ software (DSP, Direct Strip Processing, v9) [4].

\section{RESULTS}

\section{I Reheating Conditions at $1250^{\circ} \mathrm{C}$ (Cold Charging)}

After reheating at $1250^{\circ} \mathrm{C}$, the mean austenite grain size is $210 \mu \mathrm{m}$ and all $\mathrm{Nb}$ is in solution, a situation close to cold charging. The austenite microstructure obtained with steel $A$ after the application of the schedule with the first

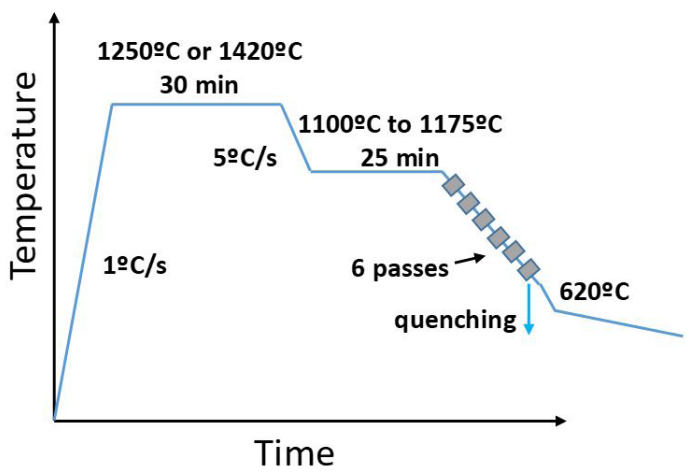

Figure I. Scheme of the multipass tests.

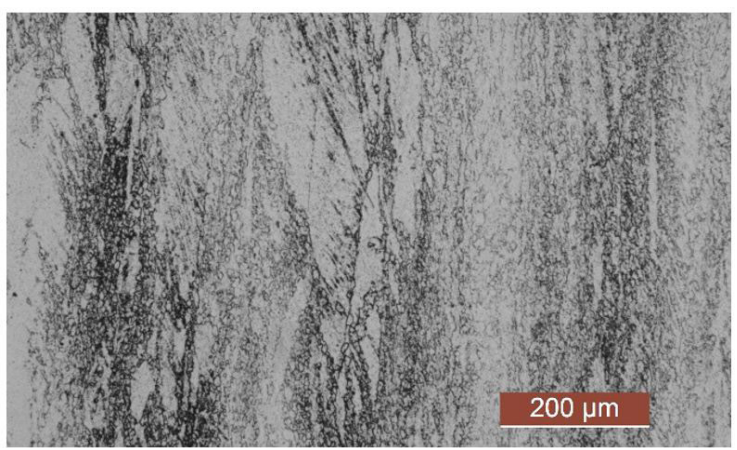

strain at $T_{1}=1040^{\circ} \mathrm{C}$ is shown in Figure 2. In the figure, some elongated non-recrystallized grains combined with very fine austenite grains can be observed.

The resulting austenite microstructure after the application of the schedule with $\mathrm{T}_{1}=1115^{\circ} \mathrm{C}$ is illustrated in Figure 3. The pancaked nature is more evident and the small equiaxed grains fraction significantly smaller than in Figure 2. Figure 4 shows the room temperature microstructures obtained after coiling simulation. For both simulations, they are mainly ferritic with some degree of heterogeneity.

Table I. Chemical composition of the steels (wt.\%)

\begin{tabular}{cccccc}
\hline Steel & $\mathbf{C}$ & $\mathbf{M n}$ & $\mathbf{S i}$ & $\mathbf{N b}$ & $\mathbf{N}$ \\
\hline $\mathrm{A}$ & 0.06 & 1.00 & 0.35 & 0.056 & 0.0100 \\
$\mathrm{~B}$ & 0.05 & 1.56 & 0.05 & 0.060 & 0.0050 \\
\hline
\end{tabular}

Table 2. Deformation conditions applied in the multipass tests

\begin{tabular}{ccccccc}
\hline Pass & \multicolumn{3}{c}{ Temp $\left({ }^{\circ} \mathbf{C}\right)$} & Strain & $\begin{array}{c}\text { Strain } \\
\text { rate }\left(\mathbf{s}^{-1}\right)\end{array}$ & $\mathbf{t}_{\mathrm{ip}}(\mathbf{s})$ \\
\hline & $1100^{*}$ & $1150 *$ & $1175^{*}$ & - & - & - \\
1 & 1040 & 1115 & 1150 & 0.5 & 2 & 5 \\
2 & 970 & 1045 & 1080 & 0.5 & 2 & 5 \\
3 & 900 & 975 & 1010 & 0.5 & 2 & 5 \\
4 & 850 & 925 & 960 & 0.3 & 5 & 3 \\
5 & 830 & 905 & 940 & 0.3 & 5 & 3 \\
6 & 820 & 895 & 930 & 0.3 & 5 & 5 \\
& $800 * *$ & $875 * *$ & $910 * *$ & - & - & - \\
\hline
\end{tabular}

*Temperature equalizing step; **Quenching from this temperature; ip: interpass time.

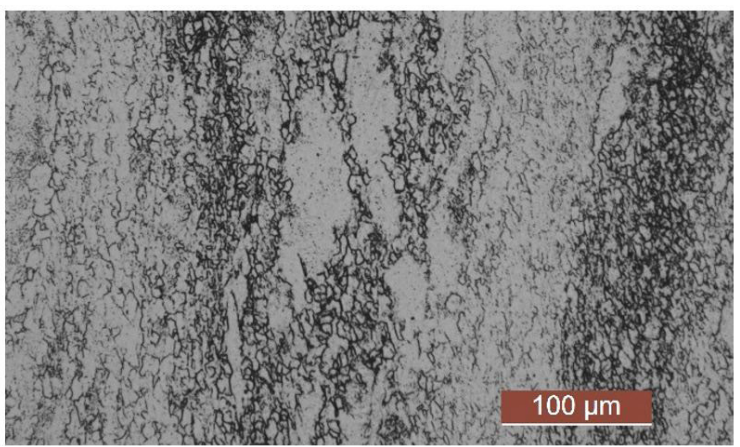

Figure 2. Austenite microstructure after quenching $\left(1250-1040^{\circ} \mathrm{C}\right.$ condition).
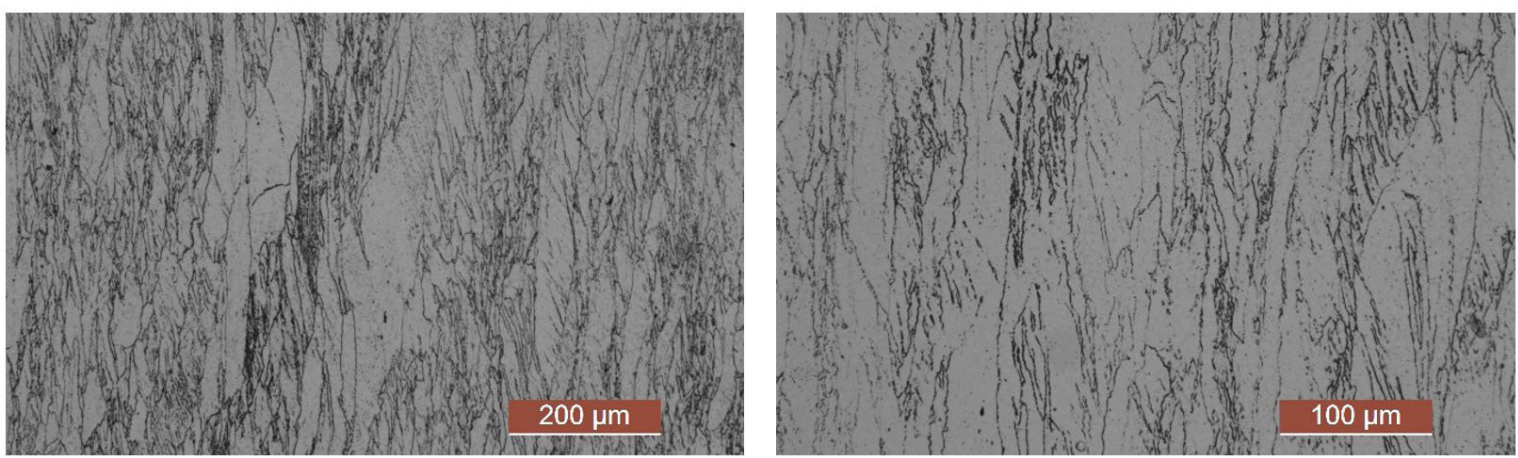

Figure 3. Austenite microstructure after quenching $\left(1250-1 \mathrm{I} I 5^{\circ} \mathrm{C}\right.$ condition). 


\subsection{Reheating Conditions at $1420^{\circ} \mathrm{C}$ (Direct Charging Simulation)}

The initial austenite microstructure consists of coarse grains, with a mean value of $\sim 600 \mu \mathrm{m}$ and some of them as big as $2 \mathrm{~mm}$ (this cycle was applied to steel B). Figure 5 shows the microstructure after quenching for $T_{1}=1040^{\circ} \mathrm{C}$ after deformation schedule application. A very elongated non-recrystallized microstructure is present and grain boundary serrations and internal microbands can be observed. Equiaxic recrystallized grains are not present. Figure 6 corresponds to the condition of $T_{1}=1150^{\circ} \mathrm{C}$. In addition

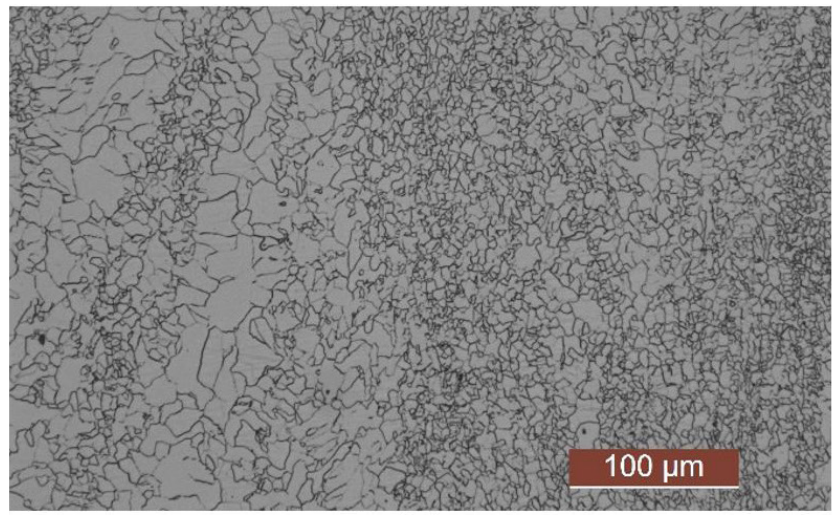

(a) to the pancaked austenite, there are small equiaxed grains heterogeneously distributed.

The corresponding room temperature microstructures are shown in Figure 7. In addition to small ferrite grains, heterogeneous areas constituted by coarse grains can be observed. The heterogeneous fraction for the condition of $T_{1}=1040^{\circ} \mathrm{C}$ is $\cong 30 \%$, while this fraction increases to $50 \%$ for $T_{1}=1150^{\circ} \mathrm{C}$. The mean ferrite grain size measured in the homogeneous areas is very fine, in the range of $3.5 \mu \mathrm{m}$. In the heterogeneous areas with coarse ferrite grains, it is possible to identify also small pearlite colonies.

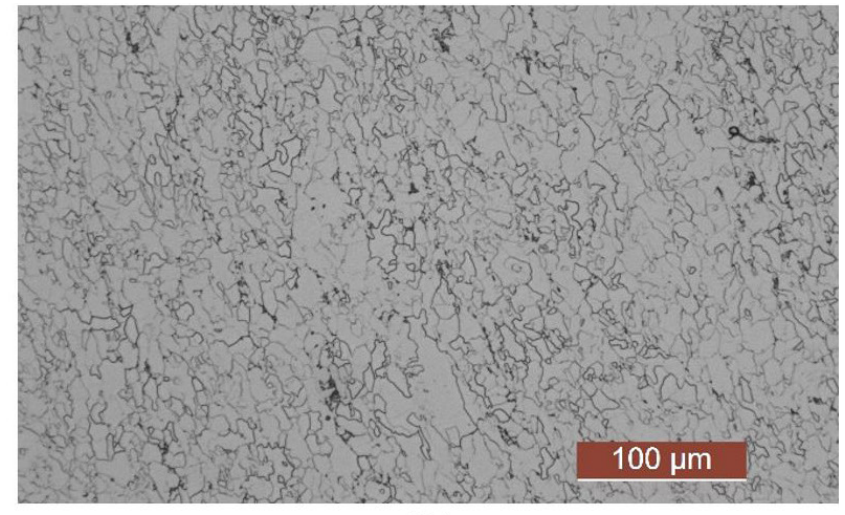

(b)

Figure 4. Room temperature microstructure (a) $1250-1040^{\circ} \mathrm{C}$; (b) $1250-1 \mathrm{I} I 5^{\circ} \mathrm{C}$.
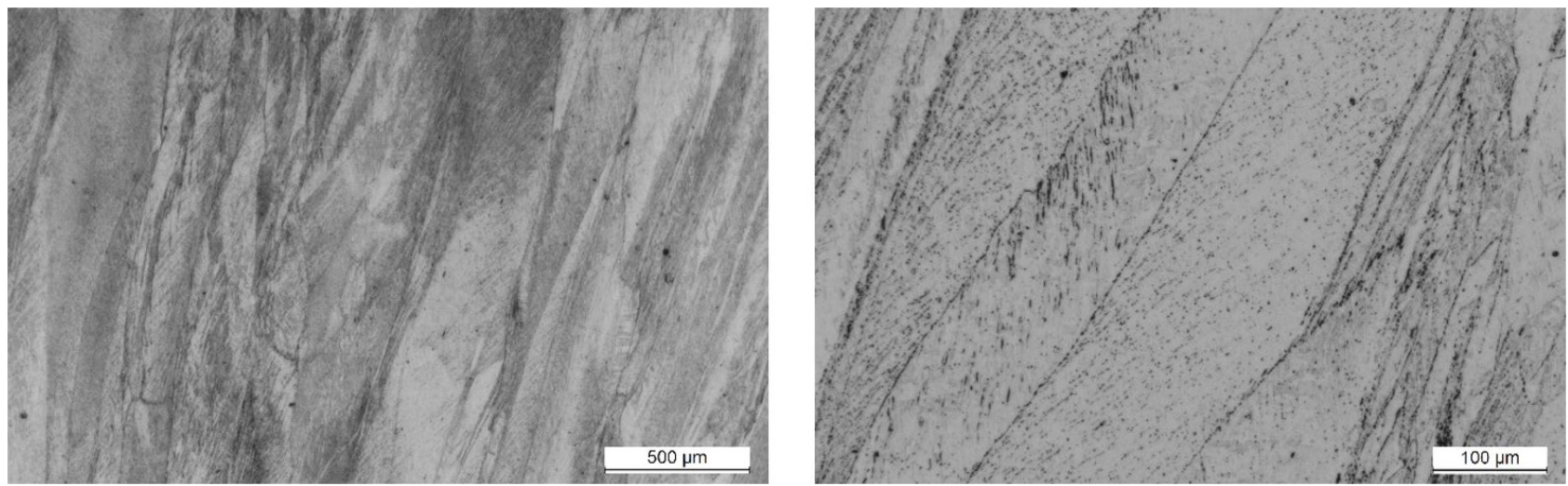

Figure 5. Austenite microstructure after quenching $\left(1420-1040^{\circ} \mathrm{C}\right.$ condition).
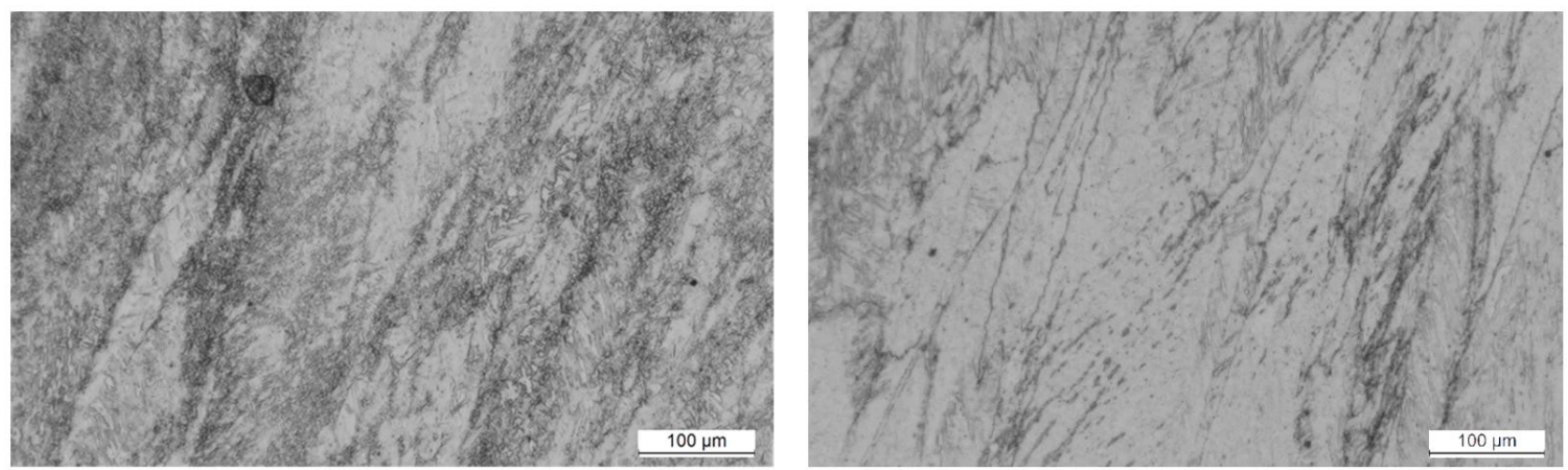

Figure 6. Austenite microstructure after quenching $\left(1420-1150^{\circ} \mathrm{C}\right.$ condition). 


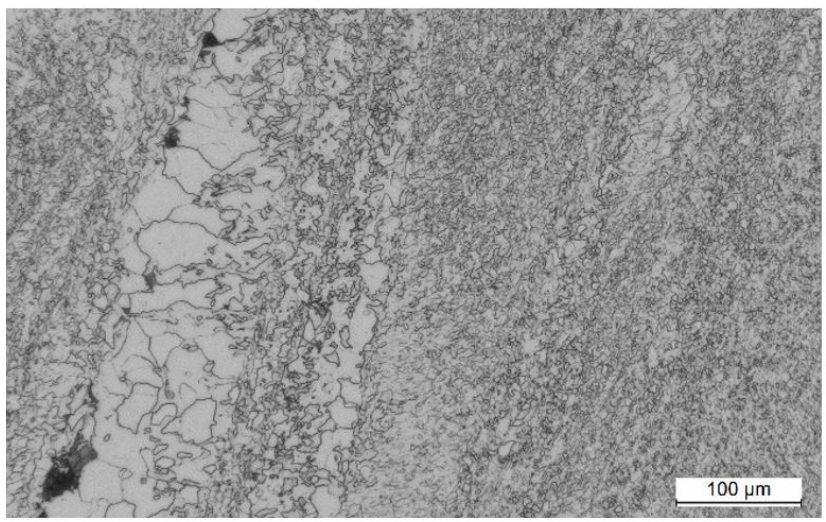

(a)

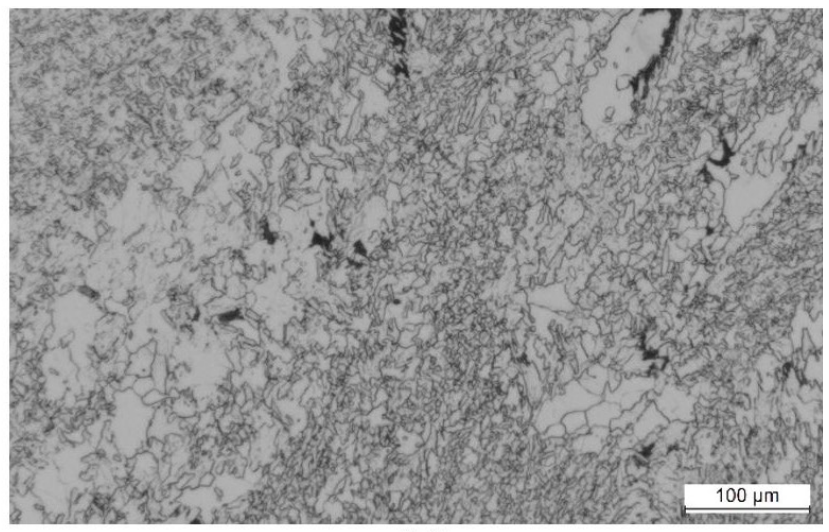

(b)

Figure 7. Room temperature microstructure (a) $1420-1040^{\circ} \mathrm{C}$; (b) $1420-1150^{\circ} \mathrm{C}$.
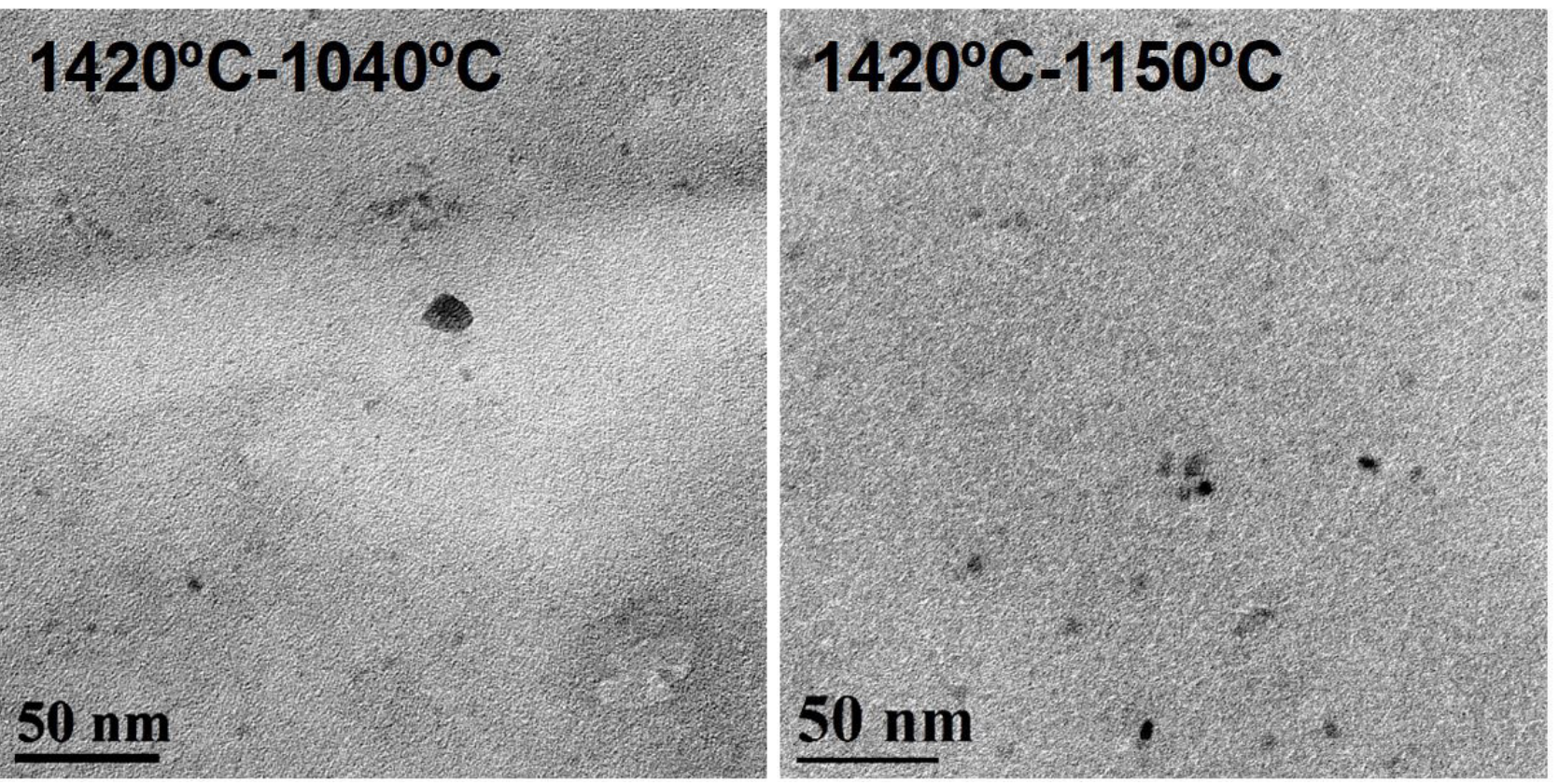

Figure 8. Fine $\mathrm{Nb}(\mathrm{C}, \mathrm{N})$ precipitates in room temperature microstructures.

\subsection{Precipitation Analysis}

TEM analysis of samples quenched before transformation shows that:

- In $1100^{\circ} \mathrm{C}$ equalization step and $\mathrm{T}_{1}=1040^{\circ} \mathrm{C}, \mathrm{Nb}(\mathrm{C}, \mathrm{N})$ precipitates with mean sizes between $20-50 \mathrm{~nm}$ were present. These particles probably precipitated during the equalization step. Some smaller particles were also observed, probably corresponding to strain induced precipitates;

- When the equalizing temperature was increased to $1175^{\circ} \mathrm{C}$ and $T_{1}=1150^{\circ} \mathrm{C}$, some particles of $20-50$ $\mathrm{nm}$ were identified, but less abundant than in the previous case. The presence of possible strain induced particles was also scarce.
In relation to room temperature microstructures, it was possible to identify a large number of very fine particles (Figure 8). Foil analysis confirmed that there was a fine $\mathrm{Nb}(\mathrm{C}, \mathrm{N})$ precipitation, in some cases randomly distributed in the matrix, and in others associated with dislocations (Figure 9).

\section{DISCUSSION}

Although in all cases a similar total reduction was applied, the conditions analyzed lead to different microstructural situations. The micrographs of Figures 2-5 indicate that both the initial austenite grain size and the rolling temperature schedule affect austenite conditioning. With the help of MicroSim model, it is possible to analyze the austenite microstructural evolution microstructure 


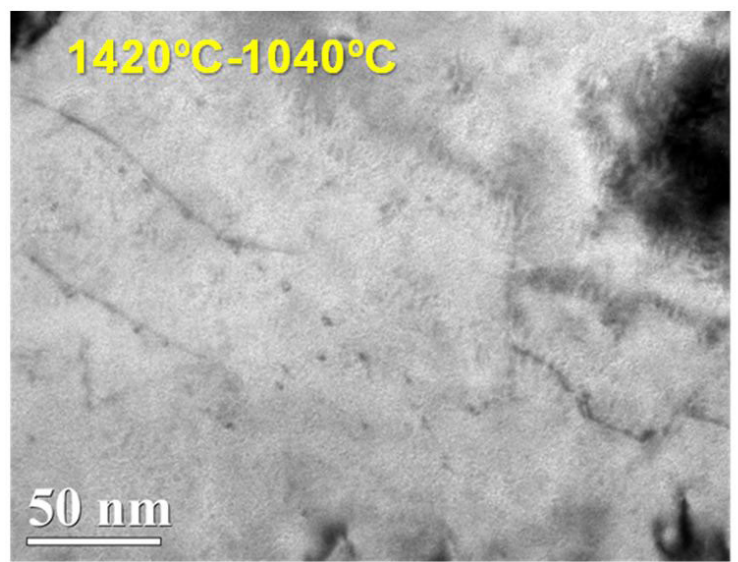

Figure 9. $\mathrm{Nb}(\mathrm{C}, \mathrm{N})$ fine precipitates present in the ferritic microstructures.

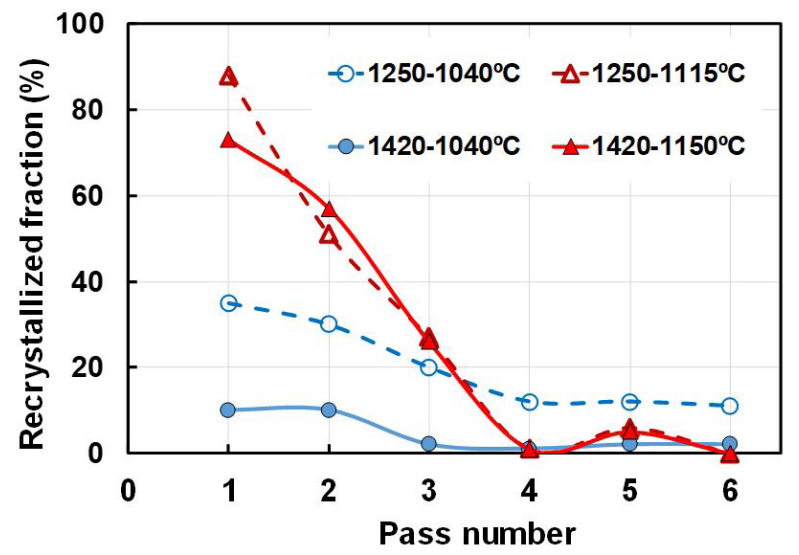

Figure 10. Recrystallized fraction evolution per pass predicted by MicroSim ${ }^{\circledR}$.

during multipass deformation. Figure 10 summarizes the results corresponding to the recrystallized fraction evolution.

In these calculations, it has been considered that only part of the nominal $\mathrm{Nb}$ is in solid solution, based on previous studies that analyzed the effect of equalizing time prior to deformation [5]. In the figure, some main differences depending on the low $\left(1040^{\circ} \mathrm{C}\right)$ or high $\left(1115-1150^{\circ} \mathrm{C}\right)$ initial deformation temperatures can be observed. In the $T_{1}=1040^{\circ} \mathrm{C}$ conditions, the recrystallized fraction remains low during all deformation sequences. This is especially relevant in direct charging simulation with coarse initial austenite grains. In this case, the recrystallized fraction predicted by the model is below $20 \%$ volume fraction during all the sequence. As the initial austenite grain size exerts a relevant role in the microstructural evolution during deformation, a specific analysis of each case will be next carried out.

The conventional approach in thermomechanical processes is to develop a complete recrystallized microstructure in the initial passes, known as Type I regime, followed by a fully pancaked microstructure before phase transformation (Type II), as the scheme of Figure II shows. Usually, the mix of recrystallized and non-recrystallized microstructures (Type III) is considered as a transient situation to avoid as a

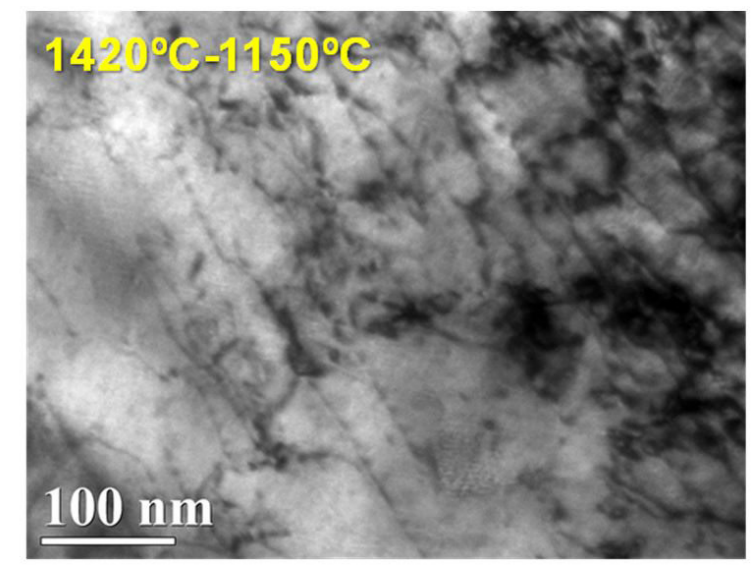

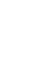

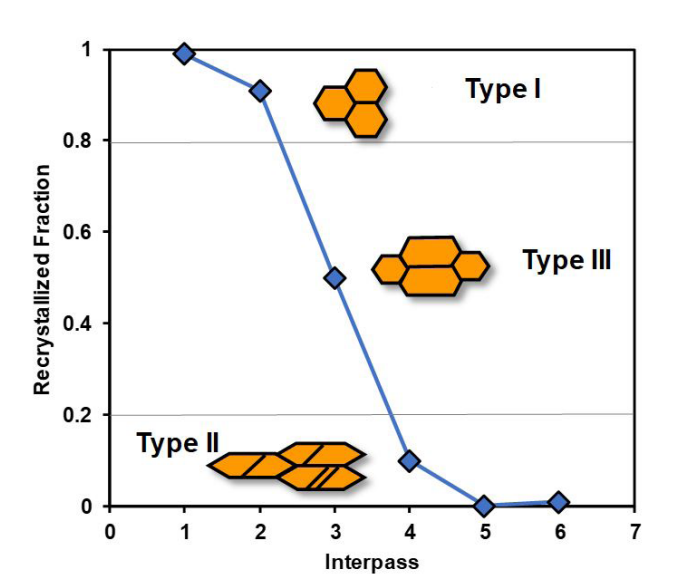

Figure II. Scheme of different regions identified as a function of the evolution of recrystallized austenite per pass.

final condition prior to transformation [6,7]. By applying this strategy, a homogeneous transformed room temperature microstructure can be obtained.

\section{I Reheating Conditions at $1250^{\circ} \mathrm{C}$}

In addition to the recrystallized fraction (Figure 10), MicroSim model provides other main results:

- For $T_{1}=1040^{\circ} \mathrm{C}$, the recrystallized fraction occurring after all the passes is a mix of static and metadynamic. On the other hand, for $\mathrm{T}_{1}=1115^{\circ} \mathrm{C}$, metadynamic (combined with static) is only relevant in the initial passes. This agrees, at least qualitatively, with the characteristics observed in Figures 2 and 3;

- In both cases, after pass 3, there is strain-induced precipitation, but more relevant for $T_{1}=1115^{\circ} \mathrm{C}$ condition.

The model predicts that, although the accumulated strain in austenite is similar in both cases, for $\mathrm{T}_{1}=1115^{\circ} \mathrm{C}$ this is due to strain-induced precipitation, while for $T_{1}=1040^{\circ} \mathrm{C}$ solute drag plays an important role. Finally, looking 
at the heterogeneity level of the quenched microstructures of Figures 2 and 3, no clear conclusions can be obtained about each strategy. After transformation, in both cases some heterogeneity level in ferrite grain sizes is observed (Figure 4). On the other hand, the main aspect to consider is that the rolling strategy identified that the recrystallization and pancaking evolution has been completely different. This can also be observed in Figure 12, which shows the accumulated strain per pass predicted by MicroSim.

\subsection{Reheating Conditions at $1420^{\circ} \mathrm{C}$}

For $T_{1}=1150^{\circ} \mathrm{C}$ the predictions are closer to the "ideal" case, although in the initial steps a high recrystallization fraction has not been achieved (Figure 10). The predictions of MicroSim indicate that, for $T_{1}=1040^{\circ} \mathrm{C}$, the coarse as-cast grains combined with low initial temperatures do not favor dynamic recrystallization activation. In addition, as strain accumulates from pass to pass, strain induced precipitation takes place before any relevant recrystallization. These predictions, suggesting a very big pancaked microstructure, agree with Figure 5. The model predicts a total accumulated strain in austenite of 2.2 before transformation, significantly higher than that observed in the $1250^{\circ} \mathrm{C}$ reheating tests (Figure I2).

In the case of $T_{1}=1150^{\circ} \mathrm{C}$, MicroSim predicts the occurrence of some dynamic and metadynamic

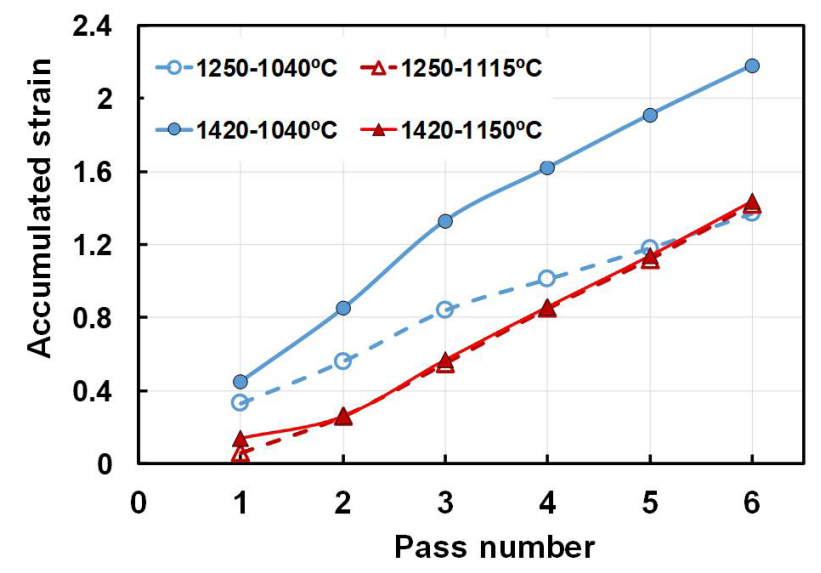

Figure 12. Accumulated strain values per pass predicted by MicroSim.

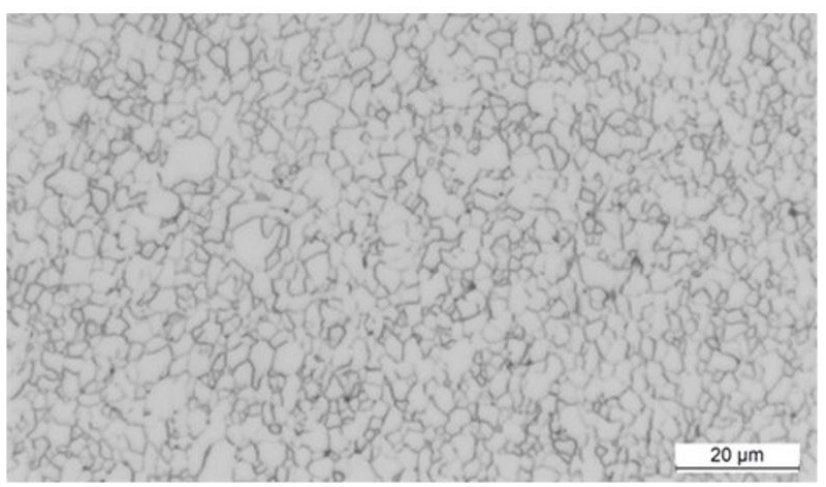

recrystallizations, in addition to the static one, due to the higher initial deformation temperatures. This is confirmed by the microstructures in Figure 6. As a result, lower strain accumulation takes place in the initial passes, delaying strain induced precipitation to interpass 3 .

In this case, the model predicts a total accumulated strain of I.44 before transformation (Figure 12). As in the $1250^{\circ} \mathrm{C}$ reheating case, the resulting strategy in both cases is very different.

The room temperature microstructure depends, in addition to other factors, on the austenite conditioning. In both cases, Figure 7, it is possible to identify very fine ferrite grains (in the range of 3-4 $\mu \mathrm{m}$ ), but in contrast to what it could be expected, the fraction of heterogeneous areas with coarse ferrite grains was lower in the $\mathrm{T}_{1}=1040^{\circ} \mathrm{C}$ condition. However, these fractions remained very high.

The microstructural analysis of the quenched samples denote that two different problems affect the heterogeneity appearance in room temperature microstructures. In the high pancaked situations, as in the case of $\mathrm{T}_{1}=1040^{\circ} \mathrm{C}$, it is possible to observe large differences in the amount of internal defects within the elongated austenite grains, as shown in Figure 5. These internal defects will enhance intragranular nucleation of ferrite grains, promoting the very fine microstructure observed in the homogeneous regions (Figure 13). In contrast, the aspect of the ferrite grains, in the heterogeneous regions (Figure 13), suggests the lack of intragranular nucleation during phase transformation and the growth of ferrite grains nucleated at grain boundaries until impingement.

The second problem to take into account is related to the activation of softening mechanisms, including different recrystallization types, characterized by an important local heterogeneity. This, combined with the different density of internal defects in the remaining non-recrystallized grains, results in the heterogeneities that are present in the final microstructure. Both aspects are probably related to the different crystallographic orientations of some austenite grains in relation to the rest of microstructure, but this remains an open question.

The analysis of the laboratory simulations shows different aspects of how $\mathrm{Nb}$ interacts with the different

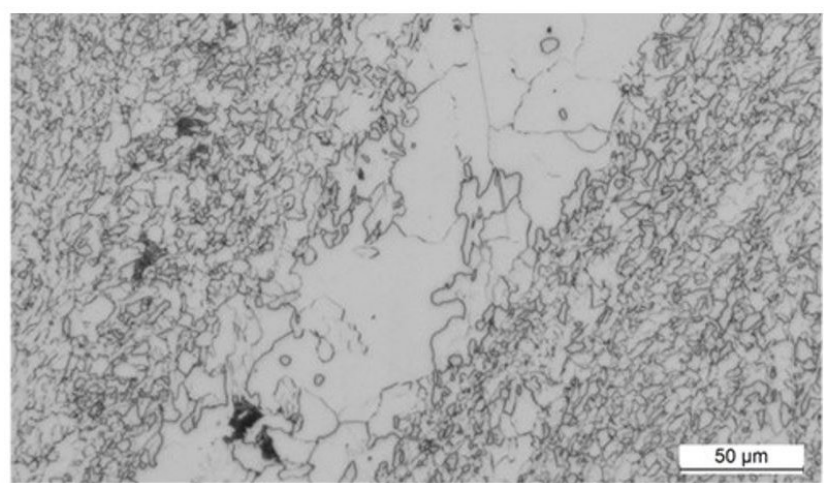

Figure 13. Homogeneous and heterogeneous ferritic regions ( $1420-1040^{\circ} \mathrm{C}$ condition). 
austenite microstructural evolution mechanisms during the simulations. For example, its role as solute drag factor delaying static recrystallization is a key factor in conditions as those happening in the $1250-1040^{\circ} \mathrm{C}$ case, while strain-induced precipitation appears as the main retarding softening mechanism in the other cases. On the other hand, in addition to the final room temperature grain refinement that both solute drag and strain-induced precipitation help to achieve, Figure 9 shows the other mechanism, precipitation hardening, that needs to be considered. The balance between "solute drag", "strain induced precipitation" and "precipitation hardening", that can be obtained with $\mathrm{Nb}$, will depend on a proper design of the thermomechanical processing parameters. And in addition to the usually accepted variables (reduction per pass, interpass time, temperature...), the nature of the austenite microstructure, including the amount of $\mathrm{Nb}$ in solution and precipitated at the entry of the first rolling pass, is another key factor in these complex interactions.

\section{CONCLUSIONS}

This study has analyzed the interactions that can take place during hot deformation between softening mechanisms, strain-induced precipitation and strain accumulation and how they affect final room temperature and microstructural homogeneity in Nb microalloyed steels. Extreme scenarios have been simulated showing that:

- Initial microstructure, both in terms of austenite grain size distribution and $\mathrm{Nb}$ precipitated or in solution, affects the evolution of the microstructure during rolling;

- As initial austenite grain size becomes coarser, more attention must be payed to austenite intragranular defect density and to the heterogeneous nature of recrystallization nucleation;

- These two characteristics need to be considered to define adequate rolling strategies, included chemistry, when high mechanical properties that require a high degree of microstructural homogeneity, become critical.

\section{Acknowledgements}

The authors would like to gratefully acknowledge Companhia Brasileira de Metalurgia e Mineração (CBMM) for funding this study.

\section{REFERENCES}

I Isasti N, López B, Rodriguez-lbabe JM, Martínez L, Hatui AK. Development of ferritic-bainitic Nb microalloyed steels by CSP route. In: Proceedings of International Symposium on Thin Slab Casting and Rolling (TSCR); 2018 Apr 25-27; Wuhan, China. China: Chinese Society for Metals; 2018. p. 80-87.

2 Linzer B, Jungbauer A, Wersching G, Viehböck A, Changjiang Y, Yao Y, et al. The new world of hot strip rolling: achievements at Rizhao steels's new ESP complex setting new standards. Berg- und Hüttenmännische Monatshefte. 2016;161:42I-428.

3 Pereda B, Lopez B, Rodriguez-lbabe JM. Relevance of static and dynamic recrystallizations on austenite grain refinement in Nb-Mo microalloyed steels. Materials Science Forum. 20 I0;638-642:3350-3355.

4 Ceit. MicroSim-DSP ${ }^{\circledR}$ software. Version. 9. San Sebastian, Spain; 2018.

5 Larzabal G, Garcia-Sesma L, Pereda B, Uranga P, Rebellato M, López B, et al. Validation of an indirect technique to quantify the amount of $\mathrm{Nb}$ in solution prior to hot rolling. In: Proceedings of the MS\&TI6; 2016 Nov 23-27; Salt Lake City, USA. Warrendale: AIST; 2016. p. 509-516.

6 Rodriguez-lbabe JM, Uranga P, Lopez B. Some aspects regarding microstructural heterogeneities during steel processing. Materials Science Forum. 2012;706-709:157-164.

7 Stalheim D. Generation of stable optimized through-thickness mechanical properties in wide, heavy-gauge structural steel plate. In: AISTech 2018: Proceedings of the Iron \& Steel Technology Conference; 20I8, Philadelphia, PA. Warrendale: Association for Iron \& Steel Technology; 2018. p. 2295-2307.

Received: 13 Dec. 2019

Accepted: 17 Dec. 2019 